danger of spread is prompt treatment with penicillin. (In at least two of the outbreaks referred to above the strains responsible were resistant to tetracycline.) In searching for sources of infection among medical attendants and other patients in the ward, it is worth remembering that the nose and throat are not the only sites which may harbour streptococci. Careful examination should be made for skin lesions, from which group A streptococci may be cultured, particularly in children, even when nose and throat cultures are negative. ${ }^{16} 17$ In addition, anal carriers of streptococci among medical attendants have been responsible for hospital outbreaks. ${ }^{14} 15$

The cases of puerperal sepsis cited above were each of them sporadic, as is usual with such infections nowadays, but several outbreaks of puerperal sepsis in maternity units have also been reported in recent years. ${ }^{18-23}$ These episodes are reminders that streptococci are still a threat to puerperal women and that the consequences of infection may be disastrous for the victims. We cannot afford to relax vigilance against streptococcal infections in attendants and contacts of women before, during, and after parturition. Reliance on treatment after infection is dangerous because of the speed with which a fulminating illness may progress to a fatal conclusion.

A source of infection in the maternity ward which may easily pass unrecognized and which is of danger both to mothers and to babies is the umbilical stump. Group A haemolytic streptococci may be carried on the apparently healthy umbilicus for several weeks after birth ${ }^{24}$ and have been responsible for outbreaks of puerperal sepsis. ${ }^{24}{ }^{25}$ C. G. M. Nicol $^{26}$ described an outbreak in a maternity unit in which seven infants, five of whom died, developed streptococcal meningitis, six other infants suffered from skin sepsis,

- British Medical fournal, 1969, 2, 195.

British Medical fournal, 1969, 2, 831

British Medical fournal, 1969, 3, 662.

British Medical fournal, 1969, 3, 662.
British Medical Fournal, 1969, 3, 788.

- Kuharic, H. A., Roberts, C. E., and Kirby, W. M. M., fournal of the American Medical Association, 1960, 174, 1779.

Parker, M. T., Maxted, W. R., and Fraser, C. A. M., British Medical fournal, 1962, 1, 1550 .

${ }^{8}$ Eickhoff, T. C., Finland, M., and Wilcox, C., American fournal of the Medical Sciences, 1965, 249, 261.

Mitchell, R. G., and Baber, K. G., Lancet, 1965, 1, 25.

10 Dadswell, J. V., fournal of Clinical Pathology, 1967, 20, 641.

11 Robertson, M. H., British Medical fournal, 1968, 3, 349.

12 Quinn, R. W., and Hillman, J. W., Archives of Environmental Health, 1965, 11, 28

13 Rountree, P. M., and Bulteau, V. G., Medical fournal of Australia, $1965,2,446$.

${ }^{14}$ McKee, W. M., Di Caprio, J. M., Roberts, C. E., and Sherris, J. C., Lancet, 1966, 2, 1007.

${ }^{15}$ Schaffner, W., Lefkowitz, L. B., Goodman, J. S., and Koenig, M. G., New England fournal of Medicine, 1969, 280, 1224.

16 Parker, M. T., Tomlinson, A. J. H., and Williams, R. E. O., fournal of Hygiene, 1955, 53, 458.

17 Markowitz, M., Bruton, H. D., Kuttner, A. G., and Cluff, L. E., Pediatrics, 1965, 35, 393.

is McCabe, W. R., and Abrams, A. A., New England fournal of Medicine, 1965, 272, 615

19 Nash, F. W., Mann, T. P., and Haydu, I. W., Postgraduate Medical fournal, 1965, 41, 182

20 Jewett, J. F., Reid, D. E., Safon, L. E., and Easterday, C. L., fournal of the American Medical Association, 1968, 206, 344

of the American Medical Association, 1968, 206, 344.
McIntyre, D. M., American fournal of Obstetrics and Gynecology, 1968, 101, 308 .

22 Mead, P. B., Ribble, J. C., and Dillon, T. F., Obstetrics and Gyneco$\log y, 1968,32,460$.

${ }_{23}$ Tancer, M. L., McManus, J. E., and Bellotti, G., American fournal of Obstetrics and Gynecology, 1969, 103, 1028.

24 Kwantes, W., and James, J. R. E., British Medical fournal, 1956, 2, 576.

${ }_{25}$ Boissard, J. M., and Eton, B., British Medical fournal, 1956, 2, 574. Nicol, C. G. M., Monthly Bulletin of the Ministry of Health and Public Health Laboratory Service, 1961, 20,68.

${ }^{27}$ Barrett, A. M., and Gresham, G. A., Lancet, 1958, 1, 347.

"Cayton, H. R., and Morris, C. S., Monthly Bulletin of the Ministry of Health and Public Health Laboratory Service, 1966, 25, 87. and eight had an infected umbilical stump. The onset of illness in those with meningitis was sudden and the course fulminating, with death occurring in the fatal cases within 36 to 48 hours. For the infant there is also the danger that the umbilicus may be the route of infection in neonatal peritonitis.

Streptococcal myositis is a rare condition and few cases have been reported in Britain. Four fatal cases that arose apparently spontaneously and a fifth case, also fatal, of a patient who developed a streptococcal abscess after arthroplasty were described by A. M. Barrett and G. A. Gresham. ${ }^{27}$ The severity and extremely fulminating course of the illness in these patients was stressed. As the authors remark, unfamiliarity with the condition is the greatest obstacle to its diagnosis. It should be considered when a febrile patient complains of acute pain and tenderness in the proximal part of one limb, which, on examination, shows muscular swelling, tenderness, and perhaps erythema. Streptococcal infections resulting from parenteral inoculations must be very rare, but streptococcal abscesses have been reported at the site of injection of diphtheria-tetanus-pertussis vaccine which had been withdrawn from a multidose vial through the same "stock" needle into sterile disposable syringes. ${ }^{28}$ The same serological type of Str. pyogenes was isolated from each of the four children affected and from the nose of an attending doctor, the throat of a nurse, and the scissors used at the clinic.

The lesson to be learned is clear: the streptococcus is still a dangerous adversary. It can kill, and do so very rapidly. The clinical picture may not give obvious clues to the existence and nature of the infection. Parturient women must be carefully protected from exposure to streptococcal infection. In searching for sources of infection it is important to look beyond the nose and throat. Impeccable techniques for injections of any kind are mandatory in order to avoid the risks of infection transmitted in this way. Fortunately the streptococcus is still very susceptible to penicillin treatmentif the cause of illness is recognized quickly enough.

\section{Long-term Anticoagulant Treatment after Myocardial Infarction}

It is a sad reflection on the limitations of clinical trials that 20 years after the introduction of oral anticoagulants their place in the long-term management of coronary artery disease is still disputed. Comparisons between the various trials that have been carried out is difficult because of differences in their design. Statistical methods adopted are often controversial. The firm conclusions of one recent trial ${ }^{1}$ were regarded by other authorities as based on inappropriate statistical methods. ${ }^{2}$ Even our own Medical Research Council trial $^{3}$ has been criticized because it was not conducted as a " double blind" study. ${ }^{4}$ Two impressions strike the unbiased observer of this vexed problem. Firstly, there is a natural reluctance for physicians to admit that their therapeutic empire has been founded on false premises or that their energies and efforts have been fruitless. Secondly, there is no longer any place for long-term anticoagulant prophylaxis in the management of a patient who has had a myocardial infarction. 
Since $1964^{5}$ a number of trials of anticoagulant therapy have been carried out in which treated and untreated patients were divided into two groups by random selection, but many of these have not been "double blind." "-8 Such "double blind" studies as have been carried out have not been in complete agreement. G. Aspenström and K. KorsanBengsten ${ }^{9}$ concluded that there was no difference in mortality between patients treated with long-term anticoagulants and untreated controls. C. Merskey and A. Drapkin in their preliminary report came to a similar conclusion, ${ }^{10}$ though their study is not yet complete. E. A. Loeliger and colleagues found no difference in mortality but a higher rate of reinfarction in the untreated patient, ${ }^{11}$ while O. J. A. T. Meuwissen and colleagues found significant benefit from anticoagulant therapy in their patients. ${ }^{12}$ An international review group has recently analysed the records of 2,205 males and 282 females included in nine controlled trials between 1950 and 1965 and could not reach an agreed decision. The only conclusion that can be drawn from these studies is that if any beneficial effect exists it must be marginal.

In their critical review of the published work up to 1960 , Sir John McMichael and E. H. O. Parry ${ }^{4}$ concluded that the value of long-term anticoagulant therapy was unproved, and this remains true today. They showed that the prospect of surviving for five years after recovery from an acute myocardial infarct was $66 \%$ in untreated patients under the age of 60 , being worse with increasing age and complications and better with improving social circumstances and completeness of recovery. The figure varies from $80 \%$ in the doctors studied by J. N. Morris and his colleagues ${ }^{14}$ to $30 \%$ in elderly patients. ${ }^{15} \mathrm{~A}$ reduction in mortality must be the main criterion for the success of anticoagulant treatment. Though the recurrence rate of infarction is also of importance, this is much more difficult to assess. In some of the reports recording favourable effects of anticoagulants patients in the control series did not survive as long as the established mean for untreated patients. Conversely it has been pointed out that

1 Conrad, L. L., Kyriacopoulos, J. D., Wiggins, C. W., and Honick, G. L., Archives of Internal Medicine, 1964, 114, 348.

Armitage, P., and Borchgrevink, C. F., Archives of Internal Medicine, $1966,270,118$

${ }^{3}$ Report of the Working Party on Anticoagulant Therapy in Coronary Thrombosis to the Medical Research Council, British Medical fournal, 1959, 2, 803 ; 1964, 2, 837.

McMichael, J., and Parry, E.H.O., Lancet, 1960, 2, 991

British Medical fournal, 1964, 2, 831

Co-operative Study, fournal of the American Medical Association, 1965, 193, 929.

Ebert, R. V., et al., fournal of the American Medical Association, $1969,207,2263$.

Lovell, R. R. H., Denborough, M. A., Nestel, P. J., and Goble, A. J., Medical fournal of Australia, 1967, 2, 97.

- Aspenström, G., and Korsan-Bengsten, K., Acta Medica Scandinavica, 1966, 176, 563.

- Merskey, C., and Drapkin, A., Blood, 1965, 25, 567.

Loeliger, E. A., et al., Acta Medica Scandinavica, 1967, 182, 549.

2 Meuwissen, O. J. A.' T., Vervoorn, A. C., Cohen, O., and Jordan, F. L. J., Thrombosis et Diathesis Haemorrhagica, 1966, Supplement No. $21,329$.

13 International Anticoagulant Review Group, Lancet, 1970, 1, 203.

4 Morris, J. N., Heady, J. A., and Barley, R. G., British Medical fournal, 1952, 1, 503.

5 Eckerström, S., Acta Medica Scandinavica, 1951, 139, Supplement No. 250.

16 Mustard, J., in Anticoagulants and Fibrinolysins, p. 433, ed. R. MacMillan and J. Mustard. Philadelphia, Lea and Febiger. 1961.

Gilchrist, A. R., and Tulloch, J. A., Scottish Medical fournal, 1956, Gilchrist,

18 Paterson, J. C., Mills, J., and Moffatt, T., Archives of Pathology, $1957,64,129$

19 Seaman, A. J., Griswold, H. E. Reaume, R. B., and Ritzmann, L. New England fournal of Medicine, 1969, 281, 115.

20 Pollard, J. W., Hamilton, M. J., Christensen, N. A., and Achor, R. W. P., Circulation, 1962, 25, 311.

21 Pastor, B. 'H., Resnick, M. E., and Rodman, T., fournal of the American Medical Association, 1962, 180, 747.

22 Bjerkelund, C. J., Acta Medica Scandinavica, 1957, 158, Supplement No. 330.

23 Marshall, J., and Shaw, D. A., Lancet, 1960, 1, 995.

24 Singer, A., and Rob, C., British Medical fournal, 1960, 2, 633. mortality figures in some series of patients treated with anticoagulants are less than a life insurance company would expect for a healthy population of the same age and sex. ${ }^{16}$

In other studies the action of anticoagulants is said to be favourable only for the early years of treatment. ${ }^{7}$ If the action of anticoagulants is to prevent arterial thrombosis there is no reason why this prophylactic action should cease. It has been shown too that mural thrombi over infarcts occur with equal frequency in patients on anticoagulants as in those not receiving any specific treatment. ${ }^{17}$ At the same time it must be remembered that recurrent thrombosis is responsible for only little more than half the deaths following myocardial infarction. ${ }^{4}$ Other factors include the thickening of atheromatous plaques and subintimal haemorrhage. ${ }^{18}$ Falls in blood pressure may also be responsible by reducing perfusion through critically narrowed vessels. ${ }^{4}$

The disillusionment in long-term anticoagulant prophylaxis receives further support in a recent report by A. J. Seaman and his colleagues. ${ }^{19}$ This was a double-blind study of 256 patients over an average period of six years, and it showed that long-term prophylactic anticoagulant therapy after acute infarction did not reduce either the mortality or the recurrence rate of infarction. In fact, more of the treated patients required admission to hospital. It is agreed that long-term anticoagulants are of no benefit to women. Any benefit to men is unproved. The physician must therefore weigh these dubious advantages against the potential risks of his treatment.

Most of the haemorrhagic complications occur while the patient's prothrombin levels are in the desired therapeutic range. ${ }^{20}$ The hazards of anticoagulant therapy are significant even in the most experienced hands. The reported incidence of bleeding among patients on anticoagulant therapy is up to $40 \%$ in those who are ambulant, though it is only serious in $2 \%$ to $10 \%$ of patients..$^{12}$ In the series reported by C. J. Bjerkelund ${ }^{22}$ lethal haemorrhage occurred in 4 out of 118 patients on anticoagulants.

While anticoagulants are of value in the treatment of venous thrombosis, this is not true of arterial thrombosis whether cerebal thrombosis ${ }^{23}$ or occlusive arterial disease of the legs. ${ }^{24}$ The inhernt dangers of this form of treatment together with the absence of any evidence of benefit indicates that the time has come to abandon the long-term use of anticoagulants after myocardial infarction.

\section{Holiday Typhoid and T.A.B.}

As a result of hygienic measures, vaccination, and chemotherapy enteric fevers are nowadays less common and less severe than they used to be. But they can still be a menace to travellers, especially to holidaymakers, who are apt to take too few, if any, precautions against them. ${ }^{1}$

In the last decade the World Health Organization has conducted a series of controlled field trials in four countries where enteric infections are endemic. ${ }^{2-5}$ These trials have proved at least two things. Firstly, it is possible by means of a monovalent typhoid vaccine to protect people to a large extent against typhoid fever. Secondly, no laboratory method of assaying a vaccine gives results that can be correlated with those of a controlled field trial in which incidence of typhoid is compared in vaccinated and unvaccinated persons. Paratyphoid fever is 